\title{
Study of outcome of the treatment with intravenous iron sucrose in moderately anaemic pregnant women
}

\author{
Kohila Kalimuthu, Vanusha Avudaithangam*
}

Department of Obstetrics and Gynecology, Saveetha Medical College and Hospital, Chennai, Tamil Nadu, India

Received: 02 August 2019

Accepted: 12 August 2019

\section{*Correspondence:}

Dr. Vanusha Avudaithangam,

E-mail: doctor.vanusha@gmail.com

Copyright: (c) the author(s), publisher and licensee Medip Academy. This is an open-access article distributed under the terms of the Creative Commons Attribution Non-Commercial License, which permits unrestricted non-commercial use, distribution, and reproduction in any medium, provided the original work is properly cited.

\begin{abstract}
Background: Moderate anaemia seen in about 15-20\% of pregnant women. Iron sucrose complex which is used intravenously for the correction of Iron deficiency anaemia. The drug has been able to raise the haemoglobin to satisfactory level when used in moderately anaemic iron deficient pregnant women. The objective of this study was to study the improvement of $\mathrm{Hb} \%$ after treatment with intravenous Iron sucrose complex in moderately anaemic pregnant women belonging to 24-32 weeks of gestational age.

Methods: 50 antenatal patients between gestational age 24-32 weeks with hemoglobin between $8-9.5 \mathrm{~g} / \mathrm{dl}$ were selected and included in this study. They were subjected to blood hemoglobin estimation, hematocrit and peripheral smear study. In each infusion, the maximum total dose administered was $200 \mathrm{mg}$ iron sucrose in $100 \mathrm{ml}$ of normal saline, slow IV infused over 30 minutes. Monitoring was done throughout the infusion to observe for any side effects. Results: Mean hemoglobin among the 50 patients before starting the therapy was $8.172 \mathrm{~g} / \mathrm{dl}$ and the mean hemoglobin at the end of one month of completing the therapy was $11.066 \mathrm{~g} / \mathrm{dl}$. The rise in mean hemoglobin i.e. the difference in the mean hemoglobin before and after treatment was $2.894 \mathrm{~g} / \mathrm{dl}$. The $\mathrm{p}$ value is 0.0001 which is statistically significant. The mean hematocrit of the 50 patients studied before starting the treatment was $26.772 \%$ with a standard deviation of 1.914 . The mean hematocrit after completing the therapy was $33.872 \%$ with a standard deviation of 1.321. The difference in the mean hematocrit was $7.100 \%$ with a $\mathrm{p}$ value of 0.0001 which is statistically significant. Conclusions: Intravenous iron sucrose complex is well tolerated and highly efficacious in improving hemoglobin, hematocrit in the treatment of iron deficiency anaemia in antenatal women.
\end{abstract}

Keywords: Haemoglobin, Hematocrit, Intravenous iron sucrose, Iron deficiency anaemia, Iron sucrose complex, Moderate anaemia

\section{INTRODUCTION}

Anaemia is defined by WHO as a haemoglobin concentration of less than $11 \mathrm{~g} / \mathrm{dl}$ of venous blood. It is the major indirect cause of maternal mortality (20-40\% of maternal deaths). ${ }^{1}$ During pregnancy, there is a great demand for iron to meet the requirement of RBC mass expansion in the mother, fetal and placental blood and blood loss at delivery.
In pregnancy, iron deficiency is exaggerated because of the ability of fetus to extract its requirement in obligatory one way direction even from iron deficient mother. ${ }^{2}$ This is aggravated by poor absorption of iron due to adverse effects of pregnancy on the gastro intestinal tract, which include nausea and vomiting, motility disorder with reflux esophagitis and indigestion.

Moderate anaemia seen in about $15-20 \%$ of pregnant women. $^{3}$ 
Over the past year, various oral, intra muscular and intravenous preparations of iron have been used for correction of iron deficiency anaemia in the pregnant patients. However, they are associated with significant side effects and it is not possible to achieve the target rise in $\mathrm{Hb}$ level in a limited time period when the patient is approaching term.

Iron sucrose complex is which is used intravenously for the correction of Iron deficiency anaemia. The drug has been able to raise the haemoglobin to satisfactory level when used in moderately anaemic iron deficient pregnant women.

The objective of this study was to study the improvement of $\mathrm{Hb} \%$ after treatment with intravenous Iron sucrose complex in moderately anaemic pregnant women belonging to 24-32 weeks of gestational age.

\section{METHODS}

Study was conducted in department of obstetrics and gynaecology, saveetha medical college hospital, chennai during the period of 1 year. Fifty antenatal patients with moderate iron deficiency anaemia with hemoglobin between $8-9.5 \mathrm{~g} / \mathrm{dl}$ were selected and included in this study.

\section{Inclusion criteria}

- Primi and multi gravida between 24-32 weeks of pregnancy

- Pregnant women with hemoglobin between 8-9.5g/dl

- Women with established iron deficiency anemia

- Singleton pregnancy.

\section{Exclusion criteria}

- Women with history of blood transfusion

- Women who are on other parenteral iron therapies

- Anemia due to causes other than iron deficiency anemia

- Women with gestational diabetes and pregnancy induced hypertension

- Medical disorders complicating pregnancy.

The 50 pregnant women, between gestational age 24-36 weeks were subjected to blood hemoglobin estimation, hematocrit and peripheral smear study.

Iron requirement is calculated by the formula. ${ }^{4}$

[2.4x (Target $\mathrm{Hb} \%$ - patient's $\mathrm{Hb} \%$ ) x weight in $\mathrm{Kg}$ ] + $1000 \mathrm{mg}$ (for iron stores)

In the formula, weight represented the patient's weight before pregnancy in kilograms, target haemoglobin was set at $11 \mathrm{~g} / \mathrm{dl}$.
In each infusion, the maximum total dose administered was $200 \mathrm{mg}$ iron sucrose in $100 \mathrm{ml}$ of normal saline, slow IV infused over 30 minutes. Monitoring was done throughout the infusion to observe for any side effects.

\section{Procedure of study}

\section{Visit I}

Information regarding patient's name, address, age and history of amenorrhea was obtained and results of general and obstetric examination were noted, maternal weight was noted.

Investigation include estimation of hemoglobin value, hematocrit and peripheral smear examination to note the type of anemia.

The patients were given $200 \mathrm{mg}$ of iron sucrose diluted in $100 \mathrm{ml}$ of $0.9 \%$ normal saline and infused over 15-20 minutes every alternate day until the required dosage is infused. ${ }^{4}$ For the infusion of iron sucrose, test dose is not needed. ${ }^{5}$

Patient was advised to avoid oral iron during iron sucrose therapy. They were advised to report any adverse effects immediately. They were explained about repeating investigations during follow-up visits after a period of 4 weeks.

\section{Visit II}

After a period of 4 weeks, the pregnant women were examined clinically and maternal weight was noted. Hemoglobin and hematocrit were done in both groups to note the improvement in values.

The side effects volunteered by the women were noted.

Hemoglobin estimation was done by automated hematology analyzer method, which is most practical, cost effective and commonly used method.

\section{RESULTS}

Fifty antenatal women after confirming iron deficiency anemia were included in this study and the required dosage of iron was infused intravenously in the form of iron sucrose complex.

\section{Demographical data particulars}

$$
\begin{array}{ll}
\text { No. of patients } & 50 \\
\text { Mean age } \pm \text { SD range } & 25.88 \pm 3.305 \\
\text { Mean gestational age } & 28.42 \pm 2.75 \\
\text { Mean BMI } & 21.58 \pm 2.52
\end{array}
$$

In this study, age of cases were ranging from 20-32 years with mean age of $25.88 \pm 3.305$ and mean BMI was 
21.58 \pm 2.52 . This was found to be statistically insignificant.

\section{Characteristics of the class studied}

Table 1: Age distribution.

\begin{tabular}{|lll|}
\hline Age & Number & Percentage \\
\hline$\leq 20$ & 2 & $4 \%$ \\
\hline $21-25$ & 22 & $44 \%$ \\
\hline $26-30$ & 21 & $42 \%$ \\
\hline$>30$ & 5 & $10 \%$ \\
\hline Total & $\mathbf{5 0}$ & $\mathbf{1 0 0 \%}$ \\
\hline
\end{tabular}

Among 50 women studied, $4 \%$ were less than or equal to 20 years, $44 \%$ of the patients belong to the age group between 21-25 years, $42 \%$ of the patients belong to the age group between $26-30$ years and $10 \%$ belong to age group above 30 years. The mean age group in our study was $25.88 \pm 3.305$ years.

Table 2: Socio economic class.

\begin{tabular}{|lll|}
\hline Socio economic class & Number & Percentage \\
\hline Class I & - & - \\
\hline Class II & - & - \\
\hline Class III & - & - \\
\hline Class IV & 12 & $24 \%$ \\
\hline Class V & 38 & $76 \%$ \\
\hline Total & $\mathbf{5 0}$ & $\mathbf{1 0 0 \%}$ \\
\hline
\end{tabular}

Among the 50 patients 38 women belongs to class $\mathrm{V}$ and 12 women belongs to class IV socio economic status and none belonged to the class I, II and class III.

Table 3: Obstetric code.

\begin{tabular}{|lll|}
\hline Gravida & Number & Percentage \\
\hline Primi & 15 & $30 \%$ \\
\hline Multi & 35 & $70 \%$ \\
\hline Total & $\mathbf{5 0}$ & $\mathbf{1 0 0 \%}$ \\
\hline
\end{tabular}

Among the 50 antenatal patients included in our study $30 \%$ were primi gravida and $70 \%$ were multi gravida who are prone for iron deficiency due to successive pregnancies.

Table 4: Mean haemoglobin.

\begin{tabular}{|llll|}
\hline Before treatment & 50 & 8.172 & 0.4704 \\
\hline After treatment & 50 & 11.066 & 0.7383 \\
\hline Change in $\mathrm{Hb} \%$ & & 2.894 & \\
\hline
\end{tabular}

Mean hemoglobin among the 50 patients before starting the therapy was $8.172 \mathrm{~g} / \mathrm{dl}$ and the mean hemoglobin at the end of one month of completing the therapy was
$11.066 \mathrm{~g} / \mathrm{dl}$. The rise in mean hemoglobin i.e. the difference in the mean hemoglobin before and after treatment was $2.894 \mathrm{~g} / \mathrm{dl}$. The $\mathrm{p}$ value is 0.0001 which is statistically significant.

Table 5: Change in hematocrit.

\begin{tabular}{|llll|}
\hline Number & $\begin{array}{l}\text { Mean } \\
\text { PCV \% }\end{array}$ & $\begin{array}{l}\text { Standard } \\
\text { deviation }\end{array}$ \\
\hline After treatment & 50 & 26.772 & 1.914 \\
\hline $\begin{array}{l}\text { Change in mean } \\
\text { PCV }\end{array}$ & 50 & 33.872 & 1.321 \\
\hline
\end{tabular}

$P$ value: 0.0001

The mean haematocrit (Hct) of the 50 patients studied before starting the treatment was $26.772 \%$ with a standard deviation of 1.914 . The mean hematocrit after completing the therapy was $33.872 \%$ with a standard deviation of 1.321 . The difference in the mean hematocrit was $7.100 \%$ with a $p$ value of 0.0001 which is statistically significant.

Table 6: Adverse effects of the drug.

\begin{tabular}{|llll|}
\hline Sr. no. & $\begin{array}{l}\text { Adverse } \\
\text { reactions }\end{array}$ & Number & Percentage \\
\hline 1 & Head ache & - & - \\
\hline 2 & Nausea/ vomiting & 1 & $2 \%$ \\
\hline 3 & Abdominal pain & - & - \\
\hline 4 & Chills and rigors & 1 & $2 \%$ \\
\hline 5 & Joint pain & - & - \\
\hline 6 & Thrombophlebitis & - & - \\
\hline 7 & Pain at injection site & - & - \\
\hline 8 & $\begin{array}{l}\text { Anaphylactic } \\
\text { reaction }\end{array}$ & - & - \\
\hline 9 & No side effects & 48 & $96 \%$ \\
\hline
\end{tabular}

Among the 50 antenatal patients in this study, the side effects were very minimal and seen in only $4 \%$. They were nausea/vomiting in $2 \%$ patients and chills and rigors in $2 \%$. There were no anaphylactic reactions noted in the study group. There were no adverse effects noted in $96 \%$ of the patients.

\section{DISCUSSION}

In our study 50 antenatal patients with iron deficiency anemia were selected according to the inclusion and exclusion criteria stated in the methodology. The iron required is calculated and given intravenously in the form of iron sucrose complex and followed up after 30 days and the results are analyzed.

In our study, $4 \%(2 / 50)$ were less than or equal to 20 years, $44 \%(22 / 50)$ of the patients belong to the age group between $21-25$ years, $42 \%(21 / 50)$ of the patients belong to the age group between 26-30 years and $10 \%$ 
$(5 / 50)$ belong to age group above 30 years. The mean age group in our study was $25.88 \pm 3.305$ years.

In our study, $76 \%(38 / 50)$ belonged to the class $\mathrm{V}$ socio economic status who were more prone for nutritional deprivation and 24\% (12/50) belonged to the class IV socio economic status and none belonged to the class I, II and class III. Hence all were in the low socio economic status.

In our study, $30 \%$ were primi gravida and $70 \%$ were multi gravida. Majority of study group were multi gravida.

\section{Comparison of outcome parameters}

\section{Change in $\mathrm{Hb} \%$}

Most studies had measured $\mathrm{Hb}$ level when the interval between last dose of IVIS, and $\mathrm{Hb}$ measurement was atleast 4 weeks. $^{6}$

In our study which included 50 antenatal patients, the mean $\mathrm{Hb}$ before starting treatment was $8.172 \mathrm{~g} / \mathrm{dl}$ and after 4 weeks of treatment was $11.066 \mathrm{~g} / \mathrm{dl}$ with a $\mathrm{p}$ value of $0.0001 \quad(p<0.05)$ which was statistically significant. The average rise in the $\mathrm{Hb}$ in the 4 weeks time was $2.894 \mathrm{~g} / \mathrm{dl}$ with a $\mathrm{p}$ value $<0.05$ which was statistically significant.

According to a study by Khurshid SR et al, journal of Pakistan medical association, which included 50 pregnant women with iron deficiency anemia $(\mathrm{Hb}<8 \mathrm{~g} / \mathrm{dl})$, the mean of hemoglobin, MCV and serum ferritin values before and after treatment was compared and concluded that $p$ value is statistically significant. ${ }^{7}$ Our study was comparable to this study.

Our study could be compared to a study by A Dede, D Uygut et al at the Zakai Tahi Burak women's health education and research hospital, division of perinatology, Turkey, which included seventy five (75) postnatal women with hemoglobin $<9 \mathrm{~g} / \mathrm{dl}$ after delivery whether vaginal or cesarean and compared the effect of intravenous iron sucrose complex versus oral ferrous sulphate and compared the results at the end of 28 days. ${ }^{8}$ The mean hemoglobin at the start of treatment was $8.2 \pm 0.6 \mathrm{~g} / \mathrm{dl}$ in both the groups. But the mean rise in hemoglobin at the end of 28 days was $12.5 \pm 1.6 \mathrm{~g} / \mathrm{dl}$ and $11.8 \pm 0.7 \mathrm{~g} / \mathrm{dl}$ in the intravenous and oral group respectively. $\mathrm{P}$ value was 0.200 which was not significant. However the rise in mean hemoglobin in the intravenous group was $4.3 . \mathrm{g} / \mathrm{dl}$.

\section{Change in hematocrit}

In our study which included 50 antenatal patients, the mean hematocrit (Hct) before starting treatment was $26.772 \%$ and after 4 weeks of treatment was $33.872 \%$ with a $\mathrm{p}$ value of $0.0001(\mathrm{p}<0.05)$ which was statistically significant. The average rise in the hematocrit in the 4 weeks time was 7.100 with a p value $<0.05$ which was statistically significant.

\section{Adverse reactions}

In our study, the side effects were very minimal and seen in only $4 \%(2 / 50)$. They were nausea/ vomiting in $2 \%$ $(1 / 50)$ patients and chills and rigors in $2 \%(1 / 50)$. There were no anaphylactic reactions noted in the study group. There were no adverse effects noted in $96 \%$ (48/50) of the patients.

In a study by Bhandal $\mathrm{N}$, Russel $\mathrm{R}$ et al, at department of anaesthesia, oxford, UK, a prospective randomized control trial which included forty four (44) post natal women with hemoglobin $<9 \mathrm{~g} / \mathrm{dl}$ at $24-48$ hours post delivery. ${ }^{9}$ There were no serious adverse effects were reported. Five women (23\%) complained of metallic taste during the infusion of the drug which is not noted in our study. Four women (18\%) complained of facial flushing, describing it as warm tingling sensation, this was reported as 'not unpleasant'. There was no hemodynamic disturbance observed either during infusion or after infusion.

In another study by Khurshid SR et al, published in, which included 50 pregnant women with iron deficiency $(\mathrm{Hb}<8 \mathrm{~g} / \mathrm{dl})$, who were treated with iron sucrose complex, only 2 patients had mild reactions. One had pain in the epigastrium and the other had restlessness. No patient had reactions of severe nature, threatening to patient's life and requiring discontinuation of infusion. Iron sucrose complex was well tolerated and safe for both mother and fetus. ${ }^{10}$

\section{CONCLUSION}

In our study Intravenous iron sucrose complex found to be highly efficacious and resulted in hemoglobin rise of $2.89 \mathrm{gm}$, and hematocrit rise of $7.1 \%$ after 4 weeks of treatment in iron deficiency anemia in 50 antenatal women. Iron sucrose complex infusion was well tolerated and safe both to the mother and the fetus since it produced nausea and vomiting in 1 woman and chills and rigors in 1 woman among the 50 antenatal women of treatment group. There were no major adverse reactions.

To conclude intravenous iron sucrose complex is safe, convenient and more effective mode of treatment of iron deficiency anemia in antenatal women. It could be used to reduce the number of blood transfusion in the antenatal period in asymptomatic women with hemoglobin between $8-9.5 \mathrm{~g} / \mathrm{dl}$.

Funding: No funding sources

Conflict of interest: None declared

Ethical approval: The study was approved by the Institutional Ethics Committee 


\section{REFERENCES}

1. Mudaliar and Menon's Clinical Obstetrics $12^{\text {th }}$ Edition by Sarala Gopalan, S Rathnakumar, and Vanitha Jain; Orient Blackswan, Chapter 20; 2015:162.

2. Breymann C. Anemia working group. Current aspects of diagnosis and therapy of iron deficiency anemia in pregnancy. Schweiz Rundsch Med Prax. 2001;90:1283-91.

3. Kalaivani K. National institute of Health and Family welfare, Munirka- Use of intravenous iron sucrose for treatment of anaemia in pregnancy. The Indian $\mathrm{J}$ Med Res. 2013;138(1):16-7.

4. Kriplani A, Mahey R. Intravenous iron sucrose therapy for moderate to severe anaemia in pregnancy. Indian J Med Res. 2013;138(1):78-82.

5. Jose A, Mahey R, Kriplani A. Comparison of ferric carboxymaltose and iron sucrose complex for treatment of iron deficiency anemia in pregnancy. BMC Preg Childbirth. 2019;54:19.

6. Haldar P, Kant S. Effect of intravenous iron sucrose on haemoglobin level, when administered in a standard dose, to anemic pregnant women in rural northern India. J Family Med Primary Care. 2018;7(4):762-8.
7. Raja KS, Janjua NB, Khokhar N. Intravenous iron sucrose complex therapy in iron deficiency anemia in the pregnant women. Rawal Med J. 2003;28:40-3.

8. Dede A, Uygur D. At the Zakai Tahi Burak women's health education and research hospital, division of perinatology, Turkey-Intravenous iron sucrose complex vs. oral ferrous sulfate for postpartum iron deficiency anemia. Int $\mathbf{J}$ Gynaecol Obstet. 2005;90(3):238-9.

9. Bhandal N, Russel R. Intravenous versus oral iron therapy for postpartum anaemia. BJOG. 2006;113(11):1248-52.

10. Qassim A, Mol BW, Grivell RM, Grzeskowiak LE. Safety and efficacy of intravenous iron polymaltose, iron sucrose and ferric carboxymaltose in pregnancy: A systematic review - Australian and New Zealand J Obstet Gynaecol. 2017;58(1).

Cite this article as: Kalimuthu K, Avudaithangam V. Study of outcome of the treatment with intravenous iron sucrose in moderately anaemic pregnant women. Int J Reprod Contracept Obstet Gynecol 2019;8:3480-4. 